\title{
Role of guinea-pig sperm autoantigens in capacitation and the acrosome reaction*
}

\author{
B. Marquant-Le Guienne† and M. De Almeida \\ Centre d'Immuno-Pathologie et d'Immunologie Expérimentale-U 23 INSERM, \\ Hopital Saint-Antoine, 184 rue du Fg St-Antoine, 75571 Paris Cedex 12, France
}

\begin{abstract}
Summary. Three autoantigens, $S, P$ and $T$, have been isolated from epididymal spermatozoa of guinea-pigs. $S$ and $P$ are soluble antigens present on the acrosomal membranes and acrosome matrix. $T$ antigen, a family of several membrane glycoproteins, is distributed over the whole cytoplasmic membrane and on the external acrosomal membrane. Specific antibodies were used to localize the antigens on capacitated and acrosome-reacted spermatozoa and to define their role in acrosome reaction. After capacitation $S$ antigen appeared on the head surface and there was an apparent clustering of $T$ antigen. Both phenomena were prevented by the presence of specific antibodies in the capacitating medium. The acrosome reaction was inhibited both by anti-T and anti-S antibodies as well as by Fab fragments of the same antibodies. The localization of $\mathrm{S}, \mathrm{P}$ and $\mathrm{T}$ antigens on the inner acrosomal membrane after the acrosome reaction suggests that they could also play a role in subsequent steps of fertilization.
\end{abstract}

\section{Introduction}

Mammalian spermatozoa must undergo a physiological change called 'capacitation' (Austin, 1951; Chang, 1951) before the occurrence of the acrosome reaction (Oliphant, 1976) and the penetration of the oocyte (Piko \& Tiler, 1964; Barros \& Austin, 1967). Immunological approaches have been used to study the involvement of different antigens in capacitation and the acrosome reaction. In the rabbit seminal plasma components as well as sperm membrane components overlaying the acrosomal region are removed during capacitation (Oliphant \& Brackett, 1973; Koehler, 1976), and the redistribution of a surface membrane glycoprotein over the acrosomal region as induced by specific antibodies is lost after capacitation (O'Rand, 1977). In the guinea-pig auto-antibodies produced against whole spermatozoa completely block the acrosome reaction of treated spermatozoa (Tung, Okada \& Yanagimachi, 1980). Further progress in this field of research requires isolated and well characterized antigens. Three autoantigens $S, P$ and $T$, have been isolated and localized on epididymal spermatozoa of guinea-pigs (Voisin \& Toullet, 1968; Toullet, Voisin \& Nemirovsky, 1973; Le Bouteiller, Toullet, Righenzi \& Voisin, 1979). Autoantigen T, an integral membrane constituent (Lefroit-Joliy, Lebar \& Voisin, 1979), is distributed over the whole spermatozoon and on the external acrosomal membrane. Autoantigens $S$ and $P$ are soluble antigens present on the acrosomal membranes as well as in the acrosomal matrix. These antigens have well defined physicochemical and immunopathological properties (Voisin \& Toullet; 1968; Toullet et al., 1973). There is some evidence that at least two of these autoantigens can interfere with fertilization events. In fact guinea-pig females immunized with $\mathbf{P}$ and $\mathbf{T}$ antigens showed a significant delay between mating and parturition (D'Almeida \& Voisin, 1979), suggesting some hindrance of fertilization. In the

\footnotetext{
* Reprint requests to Dr M. De Almeida.

† Present address: Laboratoire pour le Contrôle des Reproducteurs. 13 rue Jouët—94703 Maisons Alfort, France.
} 
present study we examined the localization of $\mathrm{S}, \mathrm{P}$ and $\mathrm{T}$ antigens on guinea-pig capacitated spermatozoa and their role in the acrosome reaction.

\section{Materials and Methods}

Immunization. Guinea-pig sperm antigens were prepared as previously described (Voisin \& Toullet, 1968; Toullet et al., 1973) from frozen epididymal spermatozoa. Antigenic preparations mixed thoroughly with Freund's complete adjuvant (FCA, Difco Lab., Detroit, MI, U.S.A.) were injected intradermally to castrated male guinea-pigs. A booster injection without FCA was performed after 1 month and the animals were bled 7 days later. Sera were inactivated at $56^{\circ} \mathrm{C}$ for $30 \mathrm{~min}$.

Preparation of immunoglobulins (IgG) and Fab fragments. The ability of guinea-pig IgG to bind protein A through Fc fragments (Forsgreen, 1968) was used to isolate IgG fractions from the sera (Hjelm, Hjelm \& Sjöquist, 1972). Original immune sera and IgG preparations were tested by indirect enzyme-linked immune absorbent assays (ELISA) as described by Engvall (1980), to compare antibody titres. The preparation of Fab fragments was carried out by papain action according to Leslie, Melamed \& Cohen (1971). The purity of the IgG and Fab preparations was controlled by Ouchterlony's method. IgG and Fab fragment concentrations were expressed as protein per ml (Bradford, 1976).

Sera and $\operatorname{IgG}$ ELISA. Aliquants of $100 \mu \mathrm{l}$ of diluted antigen $(10 \mu \mathrm{g} / \mathrm{ml})$ in bicarbonate buffer, $0.1 \mathrm{M}, \mathrm{pH} \mathrm{9.6,} \mathrm{were} \mathrm{distributed} \mathrm{into} \mathrm{wells} \mathrm{of} \mathrm{polyvinyl} \mathrm{microtitre} \mathrm{plates} \mathrm{(Linbro} \mathrm{SMRG} \mathrm{96,} \mathrm{Flow}$ Labs, VI, U.S.A.) and incubated at $37^{\circ} \mathrm{C}$ for $2 \mathrm{~h}$. The wells were washed with phosphate-buffered saline containing $0.05 \%$ Tween 20 (PBS-Tween). Then $100 \mu \mathrm{l}$ of serial dilutions of immune sera or IgG were added to the coated wells and incubated for $1 \mathrm{~h}$ at $37^{\circ} \mathrm{C}$. After 3 washings with PBSTween, $100 \mu$ of peroxidase conjugated rabbit anti-guinea pig IgG (Miles-Yeda Ltd, Rehovot, Israel), diluted $1 / 8000$ in PBS-Tween, were distributed in each well. After $1 \mathrm{~h}$ incubation at $37^{\circ} \mathrm{C}$ and 3 washings in PBS-Tween, $100 \mu$ l of chromogen substrate ABTS (2,2'-azino-di-3-ethyl benzothiazoline sulphonate; Boerhinger Mannheim 38240 Meylan, France) were added. The substrate was prepared just before use $(10 \mathrm{ml}$ citrate buffer, $0.1 \mathrm{M}, \mathrm{pH} 4,+0.1 \mathrm{ml} 0.05 \%$

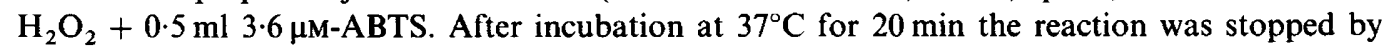
adding $100 \mu 15 \%$ SDS (sodium dodecylsulphate; Serva, Tebu S.A., 78160 Le Perray en Yvelines, France) into each well. Reactions were quantified using an automatic ELISA microtitre plate reader (Dynatech MR 580, Dynatech SARL, 94163 Rungis, France). The absorbance was determined at $405 \mathrm{~nm}$, the blank being the coated antigen incubated with the substrate. Each assay included a negative and a positive control. Serum dilutions were performed in duplicate. Antibody activity is expressed as ELISA units, one unit corresponding to the protein concentration that gives twice the absorbance of the negative control.

Spermagglutination and complement-dependent sperm immobilization were performed as described by Toullet \& Voisin (1974) except that microplates with flat bottomed wells (Falcon, Becton-Dickinson, 78530 Buc, France) were used and the reactions were read in an inverted microscope.

In-vitro treatment of guinea-pig spermatozoa by antibodies. Each cauda epididymidis was removed from mature Hartley guinea-pig males and punctured with a needle to free spermatozoa into PBS containing 0.3\% BSA (Fraction V, Sigma: Mallet Chemicals SA, 95704 Roissy, France). The sperm suspension was centrifuged at $600 \mathrm{~g}$ for $5 \mathrm{~min}$ and spermatozoa were resuspended in K-MCM (Minimum Capacitation Medium) containing 0.5\% BSA (Tung et al., 1980) or in $\mathrm{BMOC}_{3}$ (Brinster Medium for Oocytes Culture) containing 0.5\% BSA (Gibco, France).

Capacitation. Spermatozoa were allowed to incubate for $18 \mathrm{~h}$ at $37^{\circ} \mathrm{C}$ in $\mathrm{Ca}^{2+}-\mathrm{free}_{\mathrm{BMOC}}$, under mineral oil at a concentration of $10 \times 10^{6}$ spermatozoa $/ \mathrm{ml}$ in order to undergo capacitation. 
If these spermatozoa were exposed to $\mathrm{Ca}^{2+}, 80 \%$ underwent the acrosome reaction within $20 \mathrm{~min}$. Antibodies $(200 \mu \mathrm{g} / \mathrm{ml})$ were added to $100 \mu \mathrm{l}$ of sperm suspension at time 0 and samples were removed $30 \mathrm{~min}$ and $18 \mathrm{~h}$ later or after $17 \mathrm{~h} 30 \mathrm{~min}$ of capacitation, i.e. $30 \mathrm{~min}$ before the sample collection. All the samples were slowly cooled to $4^{\circ} \mathrm{C}$ and washed three times $(600 \mathrm{~g}$ for $5 \mathrm{~min})$ in $\mathrm{Ca}^{2+}$-free $\mathrm{BMOC}_{3}$. Indirect immunofluorescence was performed by incubating $100 \mu \mathrm{l}$ of each sperm suspension with $2 \mu$ l fluorescein-labelled sheep IgG antibodies against guinea-pig IgG (Pasteur Institute, Institut Pasteur Production, 75725 Paris Cedex 15, France) at $4^{\circ} \mathrm{C}$ for $30 \mathrm{~min}$. After three washings $(600 \mathrm{~g}$ for $5 \mathrm{~min}$ ) spermatozoa were observed without fixation through a Leitz Ortholux II microscope equipped with BO $200 \mathrm{~W}$ mercury lamp and K 490 interference filter; excitation filters were BG 12 and BG 38 .

Acrosome reaction. To study the acrosome reaction spermatozoa were incubated for $1-3 \mathrm{~h}$ in K-MCM containing $1.7 \mathrm{mM}^{-\mathrm{Ca}^{2+}}$ or for $16-18 \mathrm{~h}$ in $\mathrm{BMOC}_{3}$ containing $1.2 \mathrm{mM}-\mathrm{Ca}^{2+}$. In both cases spermatozoa were transferred into Petri dishes under mineral oil and mixed with the antibodies to a final volume of $100 \mu \mathrm{l}$ and a concentration of $2 \times 10^{6}$ spermatozoa $/ \mathrm{ml}$. After different incubation times at $37^{\circ} \mathrm{C}$ the acrosome reaction was recorded in 200 motile spermatozoa. Spermatozoa were considered as acrosome-reacted when they were free of acrosomal caps and showed vigorous tail movements (Fig. 1).

For the localization of $\mathrm{S}, \mathrm{P}$ and $\mathrm{T}$ antigens on acrosome-reacted spermatozoa, these spermatozoa were selected from the heterologous population obtained after incubation for $18 \mathrm{~h}$ in $\mathrm{Ca}^{2+}$-containing $\mathrm{BMOC}_{3}$. After adding Ficoll 400 (Pharmacia, France S.A., 78390 Bois d'Arcy, France) at $4 \%$ final concentration to that sperm suspension, spermatozoa were allowed to migrate to an upper layer of $\mathrm{BMOC}_{3}$ at $37^{\circ} \mathrm{C}$ for $30 \mathrm{~min}$ (Huang, Fleming \& Yanagimachi, 1981). Migrated spermatozoa were tested by indirect immunofluorescence as described above.

\section{Results}

\section{Immunological testing of anti-S, anti-P and anti-T IgGs}

The IgGs prepared from immune sera raised against $\mathrm{S}, \mathrm{P}$ and $\mathrm{T}$ autoantigens had high titres in the ELISA technique against the corresponding antigens (Table 1). Anti-T IgGs were also able to agglutinate and immobilize (in the presence of complement) guinea-pig epididymal spermatozoa. In the subsequent experiments anti-T IgGs were used at subagglutinating concentrations.
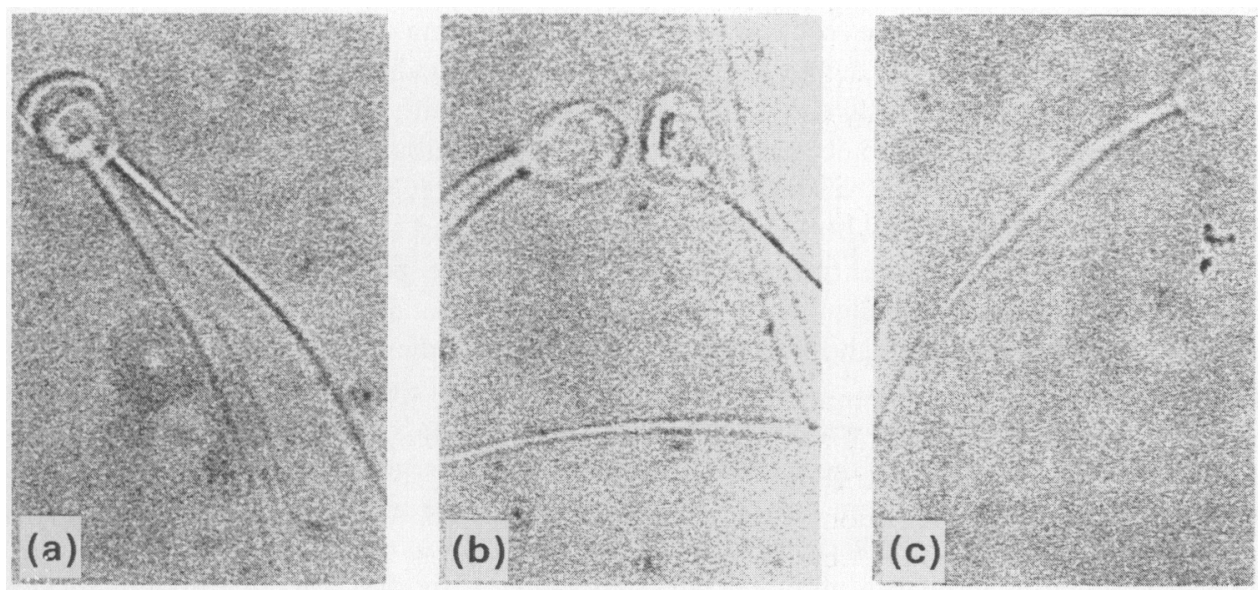

Fig. 1. Light micrographs of (a) uncapacitated, (b) capacitated and (c) acrosome-reacted living guinea-pig spermatozoa. $\times 400$. 
Table 1. Enzyme-linked immuno-absorbent assay (ELISA) to measure antibodies against guinea-pig sperm autoantigens

\begin{tabular}{lrcccc}
\hline & & \multicolumn{3}{c}{ ELISA test with sperm antigens $\dagger$} \\
\cline { 4 - 6 } IgG preparation & No. & $\begin{array}{c}\text { Protein conc. } \\
(\mu \mathrm{g} / \mathrm{ml})^{*}\end{array}$ & $\mathrm{~S}$ & $\mathrm{P}$ & $\mathrm{T}$ \\
\hline Anti-S & 2 & 100 & 6400 & - & - \\
& 6 & 70 & 1600 & - & - \\
Anti-P & 1 & 54 & - & 12800 & - \\
& 2 & 57 & - & 12800 & - \\
Anti-T & 19 & 52 & - & - & 6400 \\
\multirow{2}{*}{ Anti-DNP-BGG $\ddagger$} & 137 & 25 & - & - & 3200 \\
& - & 45 & - & - & - \\
\hline
\end{tabular}

* In the first dilution of IgG tested (1/100).

$\dagger$ Last dilution giving an absorbance $2 \times$ that of the negative control.

\$ Guinea-pig IgG anti-dinitrophenylated bovine gammaglobulin (control).

\section{Localization of $S, P$ and $T$ antigens on spermatozoa during and after capacitation}

$\mathrm{S}$ antigen was never detected on the surface of uncapacitated guinea-pig epididymal spermatozoa (Fig. 2). After incubation for $18 \mathrm{~h}$ in $\mathrm{Ca}^{2+}$-free $\mathrm{BMOC}_{3}$ a small amount of $\mathrm{S}$ antigen could be detected on the head surface of $30-40 \%$ of capacitated spermatozoa (Fig. 3). If anti-S antibodies were present in the medium during the capacitation period the appearance of $\mathbf{S}$ antigen on the surface of spermatozoa was prevented (Fig. 4).

Anti-T antibodies gave a uniform staining of the whole surface of non-capacitated spermatozoa (Fig. 5). If the same antibodies were made to react with spermatozoa at the end of the capacitation period, fluorescence in large patches over the head and the tail was observed for about $80 \%$ of the population (Fig. 6). The presence of anti-T antibodies in the capacitating medium did not allow the clustering of the $\mathrm{T}$ antigen (Fig. 7).

$P$ antigen was not detected on the surface of living spermatozoa even after capacitation.

\section{Effect of anti-S, $P$ and $T$ antibodies on the acrosome reaction}

The kinetics of the acrosome reaction in K-MCM containing $\mathrm{Ca}^{2+}$ in the presence or absence of antibodies were studied to define the optimal time of incubation (Fig. 8). The number of acrosome-reacted spermatozoa in the milieu alone increased with time. The viability of the entire population decreased from 90 to $60 \%$ between 3 and $4 \mathrm{~h}$ of incubation. The presence or absence of antibodies did not change this viability. Anti-S and anti-T IgG $(500 \mu \mathrm{g} / \mathrm{ml})$ both inhibited the acrosome reaction, apparently with the same kinetic. Anti-P and sperm unrelated anti-DNP-BGG antibodies at the same concentration did not change the percentage of acrosome-reacted spermatozoa as compared to milieu alone. An incubation time of $3 \mathrm{~h}$ was chosen to study the effect of different IgG concentrations and Fab preparations of antibodies.

As shown in Table 2, anti-T IgG significantly inhibited the acrosome reaction at all the concentrations studied. Similar results were obtained with anti-S IgG concentrations of 500 and $250 \mu \mathrm{g} / \mathrm{ml}$. A slight inhibition of the acrosome reaction was observed with $250 \mu \mathrm{g}$ anti-P IgG $/ \mathrm{ml}$.

Fab fragments prepared from anti-S and anti-T IgG were also able to block the acrosome reaction at a concentration of $500 \mu \mathrm{g} / \mathrm{ml}$.

The same phenomenon was observed with the same antibodies after incubation for $18 \mathrm{~h}$ in $\mathrm{BMOC}_{3}$ with $\mathrm{Ca}^{2+}$ (Table 3). In these conditions the percentage of acrosome-reacted spermatozoa was higher with a viability around $60 \%$. This viability was not changed in the presence of 

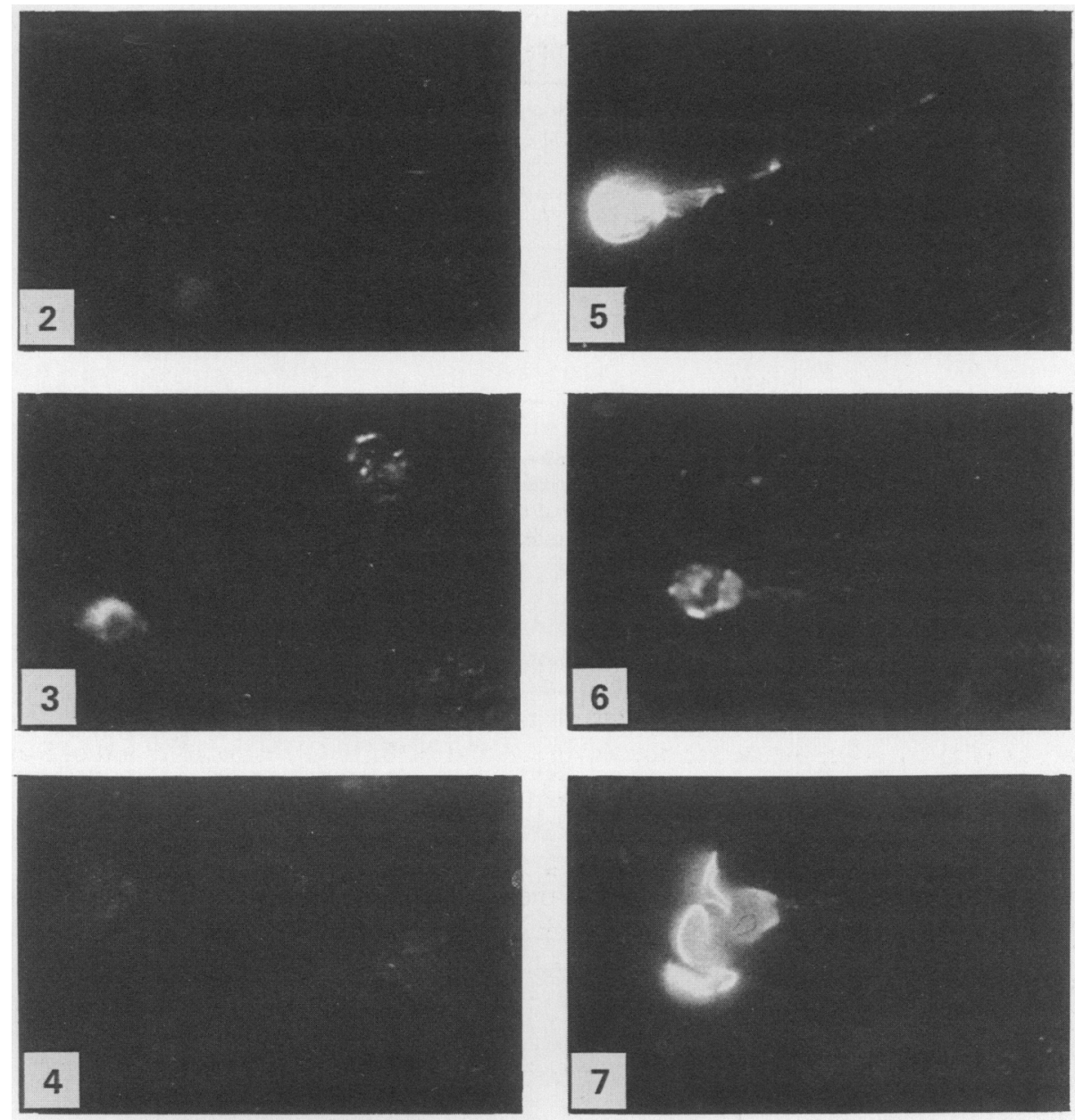

Figs 2-7. Immunofluorescent localization of $\mathrm{S}$ and $\mathrm{T}$ autoantigens on living guinea-pig spermatozoa $\times 400$.

Fig. 2. Uncapacitated spermatozoa. S antigen is not detectable.

Fig. 3. Capacitated spermatozoa $S$ antigen is present on the head surface.

Fig. 4. Spermatozoa capacitated in the presence of anti-S antibodies. $S$ antigen is not visualized.

Fig. 5. Uncapacitated spermatozoa. T antigen is present on the whole plasma membrane.

Fig. 6. Capacitated spermatozoa. Clustering of $T$ antigen on the whole plasma membrane.

Fig. 7. Spermatozoa capacitated in the presence of anti-T antibodies. $T$ antigen is uniformly distributed on the whole plasma membrane.

antibodies. Anti-T IgG still had a marked inhibitory effect but only the highest concentration of anti-S IgG inhibited the acrosome reaction.

\section{Localization of $S, P$ and $T$ antigens on acrosome-reacted spermatozoa}

The fluorescent pattern observed when acrosome-reacted spermatozoa were incubated with anti-S (Fig. 9) or anti-P (Fig. 10) antibodies was identical and localized to the inner acrosomal membrane. $T$ antigen was localized on the tail and on the whole head of the same spermatozoa (Fig. 11). S, P and T antigens were detectable on all the acrosome-reacted living spermatozoa. 
Table 2. Acrosome reaction of guinea-pig spermatozoa after incubation for $3 \mathrm{~h}$ in $\mathrm{Ca}^{2+}$-containing $\mathrm{K}-\mathrm{MCM} \dagger$ in the presence of guinea-pig anti-sperm autoantibodies

\begin{tabular}{|c|c|c|c|c|c|}
\hline \multirow[b]{2}{*}{$\begin{array}{l}\text { Protein } \\
\text { conc. }(\mu \mathrm{g} / \mathrm{ml})\end{array}$} & & \multicolumn{4}{|c|}{$\begin{array}{l}\% \text { of acrosome-reacted spermatozoa in presence } \\
\text { of antibodies }\end{array}$} \\
\hline & & $\begin{array}{c}\text { Anti- } \\
\text { DNP-BGG\& }\end{array}$ & $\begin{array}{l}\text { Anti-S } \\
\text { (312 A.U.) } \ddagger\end{array}$ & $\begin{array}{l}\text { Anti-P } \\
(1190 \text { A.U. }) \ddagger\end{array}$ & $\begin{array}{l}\text { Anti-T } \\
\text { (714 A.U. }) \ddagger\end{array}$ \\
\hline IgG & $\begin{array}{l}500 \\
250 \\
125\end{array}$ & $\begin{array}{l}31.0 \pm 0.7 \\
49 \cdot 6 \pm 2.9 \\
47.0 \pm 1.9\end{array}$ & $\begin{aligned} 8 \cdot 7 & \pm 1 \cdot 0^{* *} \\
25 \cdot 3 & \pm 1 \cdot 7^{* *} \\
43 \cdot 0 & \pm 2 \cdot 1\end{aligned}$ & $\begin{array}{l}30 \cdot 3 \pm 1 \cdot 1 \\
37 \cdot 6 \pm 1 \cdot 8^{*} \\
42 \cdot 3 \pm 1 \cdot 8\end{array}$ & $\begin{array}{r}9 \cdot 0 \pm 0.7^{* *} \\
11 \cdot 3 \pm 1 \cdot 5^{* *} \\
26 \cdot 3 \pm 1 \cdot 6^{* *}\end{array}$ \\
\hline Fab & 500 & $49 \cdot 5 \pm 2 \cdot 9$ & $12 \cdot 0 \pm 1 \cdot 6^{* *}$ & ND & $9.0 \pm 0.81^{* *}$ \\
\hline
\end{tabular}

Results are expressed as the mean \pm s.d. of 3 experiments with IgG and 2 experiments with Fab. ND, not detectable. $\dagger 40 \pm 2.7 \%$ acrosome-reacted spermatozoa in the medium alone.

$\ddagger$ Antibody activity expressed as units (A.U.) as described in 'Materials and Methods' corresponds to $500 \mu \mathrm{g}$ protein/ml.

§ Guinea-pig IgG anti-dinitrophenylated bovine gammaglobulin (control).

Significantly different from control values, ${ }^{*} P<0.02,{ }^{* *} P<0.001$ ( $t$ test).

Table 3. Acrosome reaction of guinea-pig spermatozoa after incubation for $18 \mathrm{~h}$ in $\mathrm{Ca}^{2+}$-containing $\mathrm{BMOC}_{3} \dagger$ in the presence of guinea-pig anti-sperm autoantibodies

\begin{tabular}{lcccc}
\hline & \multicolumn{4}{c}{$\%$ of acrosome-reacted spermatozoa in presence } \\
of antibodies
\end{tabular}

Results are expressed as the mean \pm s.d. of 3 experiments.

$\lceil 80 \pm 1.4 \%$ acrosome-reacted spermatozoa in the medium alone.

$\$$ Antibody activity is expressed as units as described in 'Materials and Methods'.

$\S$ Guinea-pig IgG anti-dinitrophenylated bovine gammaglobulin (control).

Significantly different from control values, ${ }^{*} P<0.02,{ }^{* *} P<0.01$ ( $t$ test).

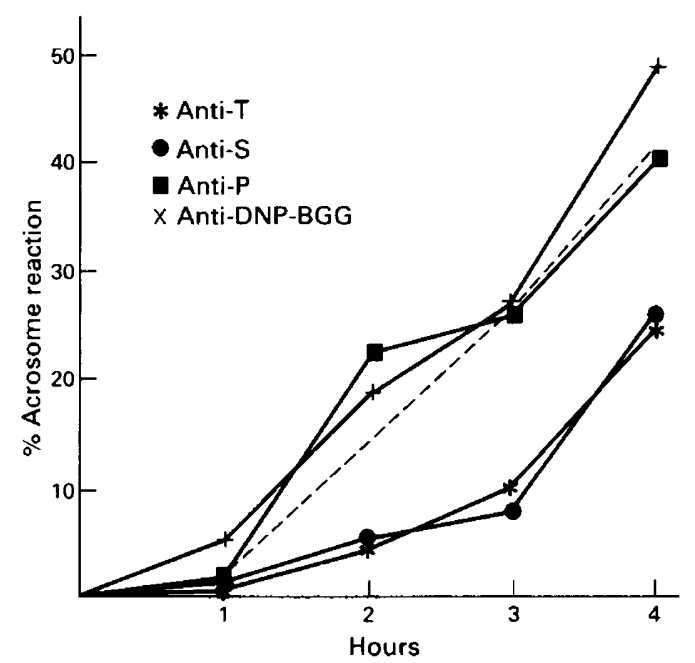

Fig. 8. Kinetics of the guinea-pig sperm acrosome reaction in $\mathrm{Ca}^{2+}$-containing $\mathrm{K}$-MEM alone $(-$.$) or in the presence of anti-T, anti-S, anti-P or anti-DNP-BGG IgGs at a concentration of$ $500 \mu \mathrm{g} / \mathrm{ml}$. 

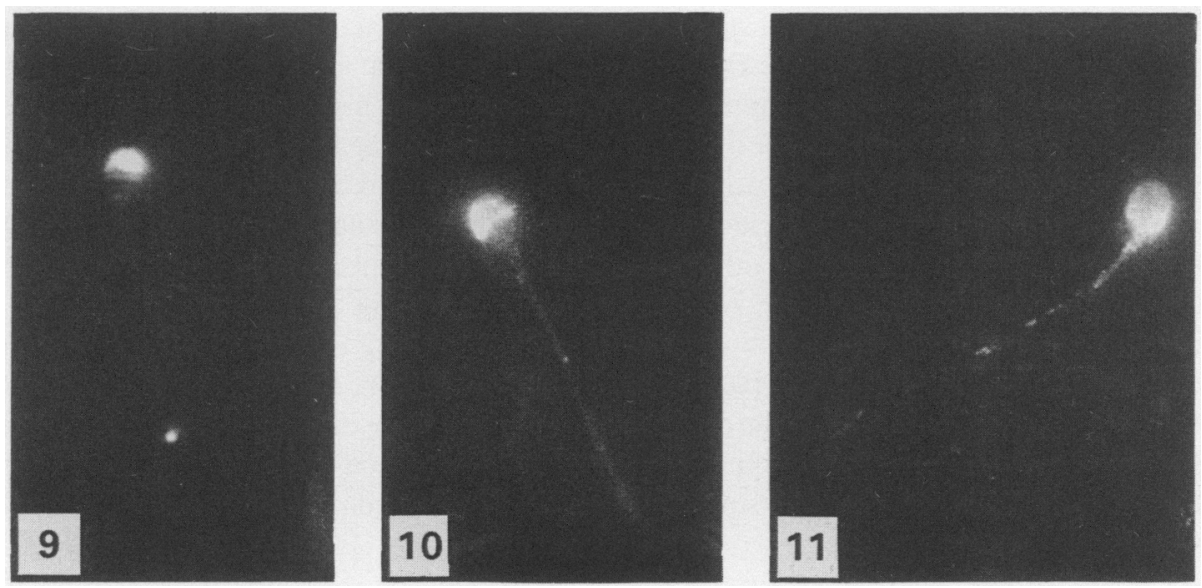

Figs 9-11. Immunofluorescent localization of $\mathrm{S}, \mathrm{P}$ and $\mathrm{T}$ antigens on guinea-pig acrosomereacted spermatozoa. $\times 250$.

Fig. 9. Staining of the inner acrosomal membrane with anti-S antibodies.

Fig. 10. Staining of the inner acrosomal membrane with anti-P antibodies.

Fig. 11. Labelling of the remaining plasma membrane as well as the inner acrosomal membrane with anti-T antibodies.

\section{Discussion}

In this study we have shown that $\mathrm{S}, \mathrm{P}$ and $\mathrm{T}$ guinea-pig sperm autoantigens are differently involved in capacitation and the acrosome reaction of guinea-pig spermatozoa from the cauda epididymidis. $S$ and $P$ are both acrosomal antigens. After capacitation $P$ remained an internal antigen but $S$ could be detected on the head surface of spermatozoa. This can be explained by the solubility of this antigen that easily diffuses in the capacitating medium (unpublished results). $S$ antigen could be secondarily absorbed on the plasma membrane as has been demonstrated for LDH-X (Erickson, Friend \& Tennenbaum, 1975). The fact that $\mathrm{S}$ antigen was not detected on the surface when spermatozoa were capacitated in the presence of specific antibodies may be explained by the formation of immune complexes and their elimination by washings.

There is an apparent clustering of the $T$ antigen during capacitation. This clustering may be due to a physiological rearrangement of the antigenic molecules as has been described for free sterols and intra-membrane particles (Friend, Orci, Perrelet \& Yanagimachi, 1977; Kinsey \& Koehler, 1978; Friend, 1980; Bradley, Rayns \& Forrester, 1980), or it may result from an increased fluidity of the membrane during capacitation (Fleming, Kosower \& Yanagimachi, 1982) that allows an antigenic aggregation induced by antibodies. A third hypothesis is that of a loss of surface antigenic sites similar to the observations of Koehler (1976). In any case, the presence of anti-T antibodies during capacitation prevented any antigenic movement on the membrane surface.

The inhibition of the acrosome reaction observed with anti- $T$ antibodies may result from the interference of these antibodies with capacitation. In fact $T$ autoantigen seems to be implicated in the acrosome reaction itself since the addition of anti- $T$ antibodies to capacitated spermatozoa $\left(\mathrm{Ca}^{2+}\right.$-free $\mathrm{BMOC}_{3}$ ) resulted in $80 \%$ inhibition of the acrosome reaction after $\mathrm{Ca}^{2+}$ addition (data not shown). We must stress that ' $T$ autoantigen' is a family of several membrane glycoproteins with clearly distinct molecular weights (Tiffoche, Kanellopoulos \& Voisin, 1985). We may speculate that some of these molecules are directly involved in the acrosome reaction. The binding of the antibodies on the corresponding antigen could act as a 'stabilizing membrane agent', limiting the 
molecular exchanges between plasma and outer acrosomal membranes important for vesiculation of the acrosome (Russell, Peterson \& Freund, 1979; Fleming \& Yanagimachi, 1981). Anti-S antibodies were able to inhibit the acrosome reaction but only at the highest concentration used. This could be explained by the lower antibody activity of these IgG preparations as compared to anti-T IgGs, or by a lower affinity of anti-S antibodies. The effect of anti-T and anti-S antibodies on the acrosome reaction are not due to steric hindrance of non-specific adjacent molecules because Fab fragments of the same antibodies still inhibited the acrosome reaction.

The inhibition of the acrosome reaction in the guinea-pig by antibodies against whole spermatozoa has been demonstrated by Tung et al. (1980). Using antibodies raised against more defined guinea-pig sperm antigens we have shown that $\mathrm{T}$ antigen(s), as was expected from its (their) localization on the surface of spermatozoa, is (are) involved in capacitation and the acrosome reaction. $S$ antigen, since it appears on the surface of spermatozoa at the end of the capacitation period, is also implicated in the acrosome reaction. The $P$ antigen is apparently not involved in these events.

After the acrosome reaction the three antigens are present on the inner acrosomal membrane. For $\mathrm{S}$ and $\mathrm{P}$ that is a normal localization in uncapacitated spermatozoa (Le Bouteiller et al., 1979). Since the $T$ antigen is absent from the inner acrosomal membrane of uncapacitated spermatozoa, it must migrate to appear there after the acrosome reaction. A similar phenomenon has been demonstrated for guinea-pig spermatozoa by using a monoclonal antibody (Myles \& Primakoff, 1984); the antigen recognized by this antibody was localized in the posterior head region of acrosomeintact spermatozoa and migrated to the inner acrosomal membrane after the acrosome reaction.

The localization of S, P and $T$ antigens after the acrosome reaction suggests they could play a role in the binding of acrosome-reacted spermatozoa to the zona pellucida and oocyte penetration. This will be the next step of the study on the biological role of these antigens in fertilization.

We thank Professor Ch. Thibault for valuable criticism of this work; C. Tiffoche for technical assistance; and $\mathrm{M}$. Sorgue for typing the manuscript.

\section{References}

Austin, C.R. (1951). Observations on the penetration of sperm into the mammalian egg. Aust. J. Sci. Res. B 4, 581-586.

Barros, C. \& Austin, C.R. (1967) In vitro fertilization and sperm acrosome reaction in the hamster. J. exp. Zool. 166, 317-323.

Bradford, M. (1976) A rapid and sensitive method for the quantitation of microgram quantities of protein utilizing the principle of protein-dye binding. Analyt. Biochem. 72, 248-254.

Bradley, M.P., Rayns, D.G. \& Forrester, I.T. (1980) Effects of filipin, digitonin and polymixin $B$ on plasma membrane of ram spermatozoa an electronic microscopic study. Archs Androl. 4, 195-204.

Chang, M.C. (1951) Fertilizing capacity of spermatozoa deposited into the fallopian tubes. Nature, Lond. 168, 697-698.

D'Almeida, M. \& Voisin, G.A. (1979) Resistance of female guinea pig fertility to efficient iso-immunization with spermatozoa antigens. J. Reprod. Immunol. 1, 237-247.

Engvall, E. (1980) Enzyme immuno assay ELISA and EMIT. Meth. Enzymol. 70, 419-439.

Erickson, R.P., Friend, D.S. \& Tennenbaum, D. (1975) Localization of lactate-dehydrogenase-X on the surface of mouse spermatozoa. Expl Cell Res. 91, $1-5$.
Fleming, A.D. \& Yanagimachi, R. (1981) Effects of various lipids on the acrosome reaction and fertilizing capacity of guinea pig spermatozoa with special reference to the possible involvement of lysophospholipids in the acrosome reaction. Gamete Res. 4, 253-273.

Fleming, A.D., Kosower, N.S. \& Yanagimachi, R. (1982) Promotion of capacitation of guinea pig spermatozoa by the membrane mobility agent, $A_{2} C$, and inhibition by the disulfide reducing agent, DTT. Gamete Res. 5 , 19. 33 .

Forsgreen, A. (1968) Protein A from Staphylococcus aureus. VI. Reaction with subunit from guinea pig $\alpha_{1}$ and $\alpha_{2}$ globulins. J. Immunol. 100, 927-930.

Friend, D.S. (1980) Freeze fracture alterations in guinea pig sperm membranes preceding gamete fusion. In Membrane-Membrane Interactions, pp. 153-165. Ed. N. B. Gilula. Raven Press, New York.

Friend, D.S., Orci, L., Perrelet, A. \& Yanagimachi, R. (1977) Membrane particle changes attending the acrosome reaction in guinea pig spermatozoa. $J$. Cell Biol. 74, 561-577.

Hjelm, H., Hjelm, K. \& Sjöquist, J. (1972) Protein A from Staphylococcus aureus. Its isolation by affinity chromatography and its use as an immunosorbent for isolation of immunoglobulins. FEBS Lett. 28, $73-76$. 
Huang, T.T.F., Fleming, A.D. \& Yanagimachi, R. (1981) Only acrosome reacted spermatozoa can bind to and penetrate zona pellucida: a study using guinea pig. $J$. exp. Zool. 217, 287-290.

Koehler, J.K. (1976) Changes in antigenic site distribution on rabbit spermatozoa after incubation in 'capacitating' media. Biol. Reprod. 15, $444-456$.

Kinsey, W.H. \& Koehler, J.K. (1978) Cell surface changes associated with in vitro capacitation of hamster sperm. J. Ultrastruct. Res. 64, 1-13.

Le Bouteiller, P., Toullet, F., Righenzi, S. \& Voisin, G.A. (1979) Ultrastructural localization of guinea pig spermatozoal autoantigens on germinal cells by immunoperoxidase techniques. J. Histochem. Cytochem. 27, 857-866.

Lefroit-Joliy, M., Lebar, R. \& Voisin, G.A. (1979) Guinea pig spermatozoal plasma $T$ autoantigen. Attempts at solubilization, purification and characterization. Int. J. Molec. Immunol. 16, 327-330.

Leslie, R.G.Q., Malamed, M.D.Z. \& Cohen, S. (1971) The products from papain and pepsin hydrolyses of guinea pig immunoglobulins $1 \mathrm{G}$ and $2 \mathrm{G}$. Biochem. J. 121, 829--837.

Myles, D.G. \& Primakoff, P. (1984) Localized surface antigens on guinea pig sperm migrate to new regions prior to fertilization. J. Cell Biol.99, 1634-164l.

Oliphant, G. (1976) Removal of sperm-bound seminal plasma components as a prerequisite to induction of rabbit acrosome reaction. Fert. Steril. 27, 28-38.

Oliphant, G. \& Brackett, B.G. (1973) Immunological assessment of surface changes of rabbit sperm undergoing capacitation. Biol. Reprod. 9, 404-414.
O'Rand, M. (1977) Restriction of a sperm surface antigens mobility during capacitation. Devl Biol. 55, 260-270.

Piko, L. \& Tyler, A. (1964) Fine structural studies of sperm penetration in the rat. Proc. 5th Int. Congr. Anim. Reprod. \& A.I. Trento 2, 372-377.

Russell, L., Peterson, R. \& Freund, M. (1979) Direct evidence for formation of hybrid vesicles by fusion of plasma and outer acrosomal membranes during the acrosome reaction in boar spermatozoa. J. exp. Zool. 208, 41-56.

Tiffoche, C., Kanellopoulos, J. \& Voisin, G.A. (1985) Solubilization and characterization of guinea-pig spermatozoal plasma membrane $\mathrm{T}$ auto-antigen. Fedn Proc. Fedn Am. Socs exp. Biol. 44, 959, Abstr.

Toullet, F. \& Voisin, G.A. (1974) Spermotoxic, spermagglutinating and cytotoxic activities of guinea pig autoantibodies to sperm autoantigen T. J. Reprod. Fert. 37, 299-313.

Toullet, F., Voisin, G.A. \& Nemirovsky, M. (1973) Histoimmunochemical localization of three guinea pig spermatozoal autoantigens. Immunology 24, $635-653$.

Tung, K.S.K., Okada, A. \& Yanagimachi, R. (1980) Sperm autoantigens and fertilization. I. Effect of antisperm autoantibodies on rouleaux formation, viability, and acrosome reaction of guinea pig spermatozoa. Biol. Reprod. 23, 877-886.

Voisin, G.A. \& Toullet, F. (1968) Etude sur l'orchite aspermatogénétique autoimmune et les autoantigènes de spermatozoïdes chez le cobaye. Annls Inst. Pasteur, Paris 114, 727-755.

Received 22 July 1985 